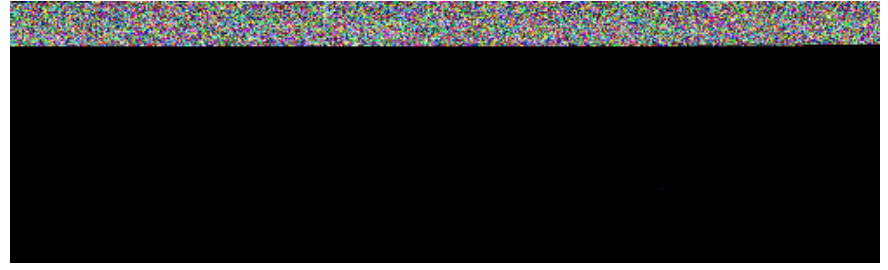

This information is current as of April 26, 2023.

\title{
Access-Site Complications in Mechanical Thrombectomy for Acute Ischemic Stroke: A Review of Prospective Trials
}

S.Z. Shapiro, K.A. Sabacinski, K. Mantripragada, S.S. Shah, A.A. Stein, N.B. Echeverry, G.A. MacKinnon and B.M. Snelling

AJNR Am J Neuroradiol 2020, 41 (3) 477-481

doi: https://doi.org/10.3174/ajnr.A6423

http://www.ajnr.org/content/41/3/477 


\title{
Access-Site Complications in Mechanical Thrombectomy for Acute Ischemic Stroke: A Review of Prospective Trials
}

\author{
(D) S.Z. Shapiro, (D).A. Sabacinski, (D) K. Mantripragada, (D)S.S. Shah, (D)A.A. Stein, (DN.B. Echeverry, (D) G.A. MacKinnon, and
}

(D) B.M. Snelling

\begin{abstract}
BACKGROUND: A shift has occurred in interventional cardiology from transfemoral to transradial access due to a $70 \%-80 \%$ decrease in complications. This shift has not yet taken place in other interventional specialties, perhaps owing to the lack of generalizability of findings in the cardiology data.
\end{abstract}

PURPOSE: Our aim was to assess data from the recent mechanical thrombectomy prospective trials to better understand the access-site complication rate.

DATA SOURCES: Articles were systematically sourced from the National Center for Biotechnology Information PubMed archive.

STUDY SELECTION: According to the Preferred Reporting Items for Systematic Reviews and Meta-Analysis guidelines, prospective, randomized controlled trials published after 2008 with mention of major and/or minor femoral access-site complications in neuroendovascular mechanical thrombectomies were included.

DATA ANALYSIS: Major and minor femoral access-site complications were extracted. A total complication rate was calculated with major access-site complications alone and combined with minor access-site complications.

DATA SYNTHESIS: Seven prospective studies of 339 total screened met the inclusion criteria. Eleven major access-site complications were identified in of 660 total interventions, revealing a major access-site complication rate of $1.67 \%$ for patients undergoing mechanical thrombectomy with transfemoral access. If minor access-site complications were included, 35 total incidents were detected in 763 interventions, resulting in a total complication rate of $4.59 \%$.

LIMITATIONS: Multiple unspecified vessel and procedure-related complications were mentioned in the studies.

CONCLUSIONS: The overall rate of major access-site complications was $1.67 \%$ in this review, which is not low and poses a risk to patients. We suggest further investigation into the feasibility and complication rates of alternative access sites for neurointerventional procedures.

ABBREVIATION: PRISMA = Preferred Reporting Items for Systematic Reviews and Meta-Analysis

$\mathbf{T}$ he field of interventional cardiology in the United States and internationally has shifted away from transfemoral access to transradial access, given the profound safety benefits, including a remarkable reduction in access-site complications such as major/minor bleeding, pseudoaneurysm, and hematoma

Received September 22, 2019; accepted after revision January 7, 2020.

From Florida Atlantic University Charles E. Schmidt College of Medicine (S.Z.S. K.A.S., K.M., N.B.E., G.A.M., B.M.S.), Boca Raton, Florida; University of Miami Miller School of Medicine (S.S.S.), Miami, Florida; Department of Neurological Surgery (A.A.S.), New York Medical College, Valhalla, New York; and Marcus Neuroscience Institute (B.M.S.), Boca Raton Regional Hospital, Boca Raton, Florida.

Please address correspondence to Brian M. Snelling, MD, Marcus Neuroscience Institute, Boca Raton Regional Hospital, 800 Meadows Rd, Boca Raton, FL 3348; e-mail: brian.m.snelling@gmail.com

http://dx.doi.org/10.3174/ajnr.A6423 development. ${ }^{1-7}$ Transradial access also leads to earlier ambulation postoperatively, shorter hospital stays, reduced costs, and improved patient satisfaction. ${ }^{5,6}$ Furthermore, successful transradial access has been reported in cases of failed transfemoral access secondary to tortuosity, stenosis near the aortic arch, bilateral iliac occlusions, and aortic dissection. ${ }^{8}$ Despite numerous prospective, randomized trials in the interventional cardiology literature, a shift away from transfemoral access toward transradial access in neurointerventional surgery has not yet been realized, with only $0.3 \%-4.5 \%$ of patients undergoing thrombectomy having transradial access in cerebrovascular interventions. ${ }^{9}$

Multiple reasons behind this slower adoption include the learning curve associated with accessing the cerebrovasculature via transradial access ${ }^{10}$ and anatomic variants complicating radial 
access with failure to reach the anterior cerebral vasculature, reported to be due to proximal left common carotid and right subclavian tortuosity, while failure to catheterize the vertebral arteries has been reported due to acute angulation and proximal origin of the vertebral arteries. ${ }^{11}$ Other reasons for the slower adoption include difficulty accessing the cerebrovasculature using current transfemoral devices and a perceived lack of transfemoral-access complications during neurointerventional procedures.

Furthermore, there is the question of whether the wealth of transfemoral access data from interventional cardiology is generalizable to our specialty, owing to differences in anticoagulation regimens, procedural type, and access and hemostasis regimens. For example, in cardiology, $6 \mathrm{~F}$ is the largest diameter catheter that could be effectively used via the transradial access. ${ }^{12}$ Prior studies in animal models have shown that the minimal innercatheter diameter needed for successful thrombectomy of the middle cerebral or internal carotid arteries is $>0.040$ inches and $>0.064$ inches, respectively, thus presenting a limitation in the minimum catheter size with which thrombectomy can be effectively performed via transradial access. ${ }^{13}$

We sought to obtain an objective understanding of transfemoral access-site complications in our own field and performed a systematic review of the prospective trial data regarding mechanical thrombectomy.

\section{MATERIALS AND METHODS}

\section{Search and Information Sources}

This review was performed in accordance with the Preferred Reporting Items for Systematic Reviews and Meta-Analyses (PRISMA). The PRISMA statement consists of a 27-item checklist and a 4-phase flow diagram. ${ }^{14}$ The aim of the PRISMA statement is to help authors improve the reporting of systematic reviews and meta-analyses. In addition to the PRISMA statement, a supporting explanation and elaboration document has been produced following the style used for other reporting guidelines. $^{15}$

Articles were sourced from the National Center for Biotechnology Information PubMed archive, the New England Journal of Medicine, Stroke, and Lancet Neurology. The search terminology entered into the PubMed archive included "mechanical thrombectomy + prospective OR mechanical thrombectomy + RCT," to locate the specific articles analyzed in this review. Articles considered for the review were only those published from 2008 to 2018 .

\section{Eligibility Criteria and Study Selection}

Articles included in this review had to meet the following criteria: prospective, randomized controlled trials. Studies that did not specifically identify groin or access-site complications were deemed ineligible, including several large transfemoral thrombectomy trials such as A Direct Aspiration, First Pass Technique (ADAPT), Multicenter Randomized Clinical Trial of Endovascular Treatment for Acute Ischemic Stroke in the Netherlands (MR CLEAN), and Solitaire With the Intention For Thrombectomy as Primary Endovascular Treatment (SWIFT PRIME), and were excluded from this review because these studies failed to identify access-site complications specifically, instead grouping them under overall procedural complications. Accordingly, 3 full-text articles that met the initial screening criteria were subsequently excluded. ${ }^{16-18}$ Serious transfemoral access-site complications were assessed in mechanical thrombectomies during an acute ischemic stroke. In the context of the included articles, serious complications/adverse events are defined as complications that meet any of the following criteria: resulted in a $>3-g$ hemoglobin or a $10 \%$ hematocrit drop, required surgical/interventional radiology intervention, required transfusion, prolonged the patient's stay in the hospital, or resulted in death. Examples include groin hematoma requiring transfusion, artery dissection, pseudoaneurysm, and occlusion requiring embolectomy. Studies that addressed only minor access-site complications (ie, accesssite ecchymosis) were excluded. Any studies using nonfemoral access-sites, written in a language other than English, and written before 2008 were also excluded (Figure).

\section{Data Collection Process}

Articles were compiled into a single data base from which identical and irrelevant articles were removed. Of the remaining articles, 7 articles met the inclusion criteria. ${ }^{19-25}$ The 7 publications included were critically evaluated by the authors, and access-site complication rates (major, minor, and total) were extracted and compiled into a single databank.

\section{RESULTS}

\section{Individual Study Characteristics}

The methodology for each clinical trial is summarized in Table 1. Of note, the studies differed in device use for mechanical thrombectomy, timing of intervention, location of vessel occlusion, and tPA administration.

\section{Data Analysis}

The access-site complication rates for each of the studies (Table 2) ranged from $0 \%$ to $11.65 \%$. Access-site complication rates were calculated by dividing the total number of access-site complications by the total number of participants in the mechanical thrombectomy arm of each study. The access-site complication rate, including both major and minor adverse events, gleaned from pooled data was 35/763 (4.59\%). Subgroup analysis revealed that 11 major access-site complications were identified of 660 total interventions, revealing a major access-site complication rate of $1.67 \%$ for patients undergoing mechanical thrombectomy with transfemoral access.

There is mention of vessel dissections and perforations in these studies; however, the vessel was unspecified in all cases.

\section{DISCUSSION}

The clinical efficacy of mechanical thrombectomy in the management of acute ischemic stroke has been investigated in numerous randomized controlled trials. While the benefits and indications of mechanical thrombectomy continue to unfold, there is a paucity of research into the access-site-associated complications from these procedures.

Prior retrospective series likely underreported the rate of transfemoral access-site complications ${ }^{26}$ because these studies may not include major, non-life-threatening complications. 
- Database: NCBI PubMed

- Search term: mechanical thrombectomy + prospective OR mechanical thrombectomy + RCT

- Filters: date range $01 / 01 / 2008-12 / 31 / 2018$
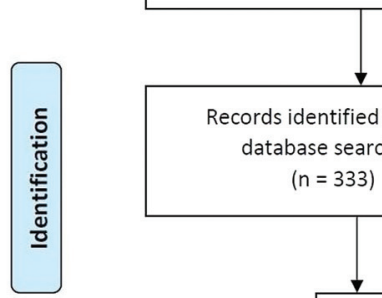

Records identified through database searching $(n=333)$

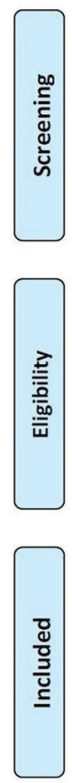

Additional records identified through other sources $(n=6)$

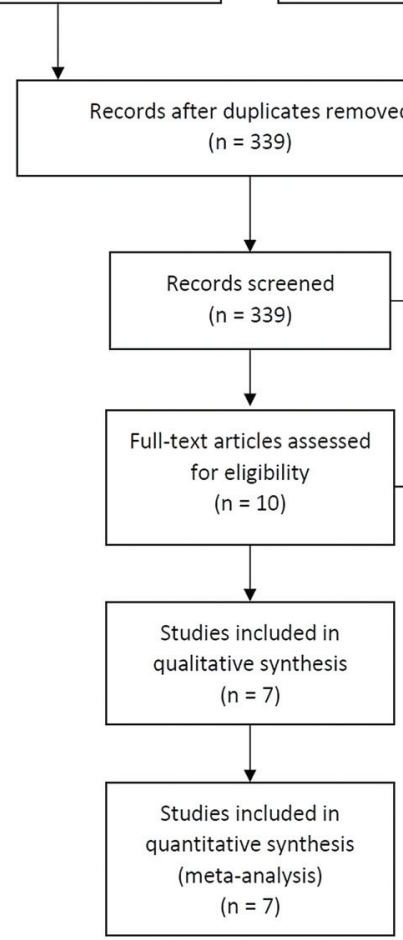

FIGURE. PRISMA flowchart.

Thus, our current understanding of access-site complications is limited, given the inherent limitations of retrospective review. This study sought to use high-level evidence to more accurately estimate the incidence of transfemoral access-site complications.

Our review found that the rate of serious access-site complications related to transfemoral access in mechanical thrombectomy was $1.67 \%$, demonstrating that adverse events occurred in a notable percentage of transfemoral access stroke interventions. It is quite possible that the true rate of adverse events in our review was even greater than the reported figure because there were a number of adverse events that may have been access-siterelated but could not be confirmed due to ambiguity in adverse event reporting in supplementary appendices.

Our findings are similar to meta-analyses on transfemoral access-site complications in interventional cardiology, which range from $2.2 \%$ to $4.8 \% .{ }^{27}$ Despite the technical differences between transfemoral access in interventional cardiology and stroke interventions, such as anticoagulation regimens, procedures, procedure lengths, and access/closure techniques and devices, access-site complication rates are similar. This similarity suggests that the access-site itself, as the consistent factor between the 2 interventions, may play a larger role in the development of complications than expected and that these complications are, in essence, specialty agnostic.

In evaluating the limitations of our included trials, it is pertinent to differentiate major and minor access-site complications. Major access-site complications are defined as any complication that either requires further surgical intervention or prolongs the patient's hospital stay, consistent with definitions in most stroke trials. These major access-site complications include groin hematoma requiring transfusion and arterial dissection. Minor access-site complications are defined as complications that do not meet major criteria but were recorded in the trials. The minor access-site complications recorded in the studies were ecchymoses, local infection, and minor self-limiting femoral hematomas. Although our review sought to identify and report these major and minor access-site complications, all included studies except 1 (Endovascular Treatment for Small Core and Proximal Occlusion Ischemic Stroke [ESCAPE] $)^{20}$ did not report minor complications. Lack of routine postprocedural sonography may have contributed to the underreporting of these complications.

When reporting vascular complications, many of the included studies did not specify a vessel. This vessel could be the femoral artery, and this would increase the access-site complication rate. Conversely, vessel complications in the cerebral vasculature would decrease the major-site-associated adverse event rate. Furthermore, there are complications listed in supplementary indices that are vague. Some of these include "arterial perforation," "vessel occlusion," and "vessel dissection." These complications may relate to the access-site; however, we could not be sure.

Last, the 4 studies that were excluded during eligibility assessment of access-site-associated adverse events may have altered the adverse event rate if details regarding these events were appropriately reported. Specifically, the Solitaire Flow Restoration Thrombectomy for Acute Revascularization (STAR) and Mechanical Embolus Removal in Cerebral Ischemia (MERCI) trials cited procedure-related adverse events and vessel dissections, and Endovascular Therapy Following Imaging Evaluation for Ischemic Stroke 3 (DEFUSE 3) reported vascular disorders and administration-site conditions. As mentioned in the above paragraph, failure to further subclassify vessel dissections further 


\begin{tabular}{|c|c|c|c|c|c|}
\hline Study & Device Used & $\begin{array}{l}\text { Time since Stroke- } \\
\text { Symptom Onset }\end{array}$ & Vessels & IV tPA & IA tPA \\
\hline SWIFT $^{19 a}$ & $\begin{array}{l}\text { Solitaire FR (Covidien, Irvine, California); } \\
\text { Merci Retriever (Concentric Medical, } \\
\text { Mountain View, California) }\end{array}$ & $<8 \mathrm{hr}$ & $\begin{array}{c}\text { Large-vessel } \\
\text { occlusion }\end{array}$ & $\begin{array}{l}\text { Contraindicated } \\
\text { or failed }\end{array}$ & Excluded \\
\hline ESCAPE $^{20 b}$ & $\begin{array}{l}\text { Any approved neurothrombectomy } \\
\text { device }\end{array}$ & $<12 \mathrm{hr}$ & $\begin{array}{l}\text { Large-vessel } \\
\text { occlusion }\end{array}$ & Yes & Unspecified \\
\hline REVASCAT ${ }^{21 \mathrm{c}}$ & Solitaire FR & $<8 \mathrm{hr}$ & $\begin{array}{l}\text { Anterior circulation } \\
\text { occlusion }\end{array}$ & Yes & Allowed \\
\hline EXTEND IA ${ }^{22 d}$ & Solitaire FR & $<4.5 \mathrm{hr}$ & $\begin{array}{l}\text { Anterior circulation } \\
\text { occlusion }\end{array}$ & Yes & Unspecified \\
\hline DAWN ${ }^{23 e}$ & $\begin{array}{l}\text { Trevo retriever (Stryker, Kalamazoo, } \\
\text { Michigan) }\end{array}$ & $6-24 \mathrm{hr}$ & $\begin{array}{l}\text { Anterior circulation } \\
\text { occlusion }\end{array}$ & $\begin{array}{l}\text { Contraindicated } \\
\text { or failed }\end{array}$ & Excluded \\
\hline MR RESCUE ${ }^{24 f}$ & $\begin{array}{l}\text { Merci or Penumbra System (Penumbra, } \\
\text { Alameda, California) }\end{array}$ & $<8 \mathrm{hr}$ & $\begin{array}{l}\text { Large-vessel } \\
\text { occlusion }\end{array}$ & Yes & Allowed \\
\hline THRACE $^{25 g}$ & $\begin{array}{l}\text { Any approved neurothrombectomy } \\
\text { device }\end{array}$ & $<5 \mathrm{hr}$ & $\begin{array}{c}\text { Large-vessel } \\
\text { occlusion }\end{array}$ & Yes & Allowed \\
\hline $\begin{array}{l}\text { Note:-IA indicates } \\
\text { Solitaire With the } \\
\text { Endovascular Trea } \\
\text { Endovascular Reva } \\
\text { Extending the Tim } \\
\text { "Clinical Mismatch } \\
\text { Mechanical Retriev } \\
\text { Trial and Cost Effe }\end{array}$ & $\begin{array}{l}\text { tra-arterial. } \\
\text { tention For Thrombectomy (SWIFT). } \\
\text { ent for Small Core and Proximal Occlusion Ischer } \\
\text { ularization With Solitaire Device Versus Best Med } \\
\text { for Thrombolysis in Emergency Neurological Defic } \\
\text { the Triage of Wake Up and Late Presenting Strok } \\
\text { and Recanalization of Stroke Clots Using Embole } \\
\text { iveness Evaluation of Intra-arterial Thrombectomy }\end{array}$ & $\begin{array}{l}\text { Stroke (ESCAPE). } \\
\text { Therapy in Anterior Ci } \\
\text {-Intra-Arterial (EXTEND } \\
\text { Undergoing Neurointerv } \\
\text { omy (MR RESCUE). } \\
\text { Acute Ischemic Stroke }\end{array}$ & $\begin{array}{l}\text { culation Stroke Within } 8 \mathrm{Hc} \\
\text { IA). } \\
\text { ntion With Trevo (DAWN). } \\
\text { THRACE). }\end{array}$ & (REVASCAT). & \\
\hline
\end{tabular}

Table 2: Access-site complication rates

\begin{tabular}{lccc}
\hline \multicolumn{1}{c}{ Trial } & Non-Major AEs & \multicolumn{1}{c}{ Serious AEs } & TAEs \\
\hline SWIFT $^{\mathrm{a}}$ & NA & $4 / 144(2.78 \%)$ & NA \\
ESCAPE $^{\mathrm{b}}$ & $12 / 165(7.27 \%)$ & $2 / 165(1.21 \%)$ & $14 / 165(8.48 \%)$ \\
REVASCAT $^{\mathrm{c}}$ & $\mathrm{NA}$ & $\mathrm{NA}$ & $12 / 103(11.65 \%)$ \\
EXTEND-IA $^{\mathrm{d}}$ & $\mathrm{NA}$ & $1 / 35(2.86 \%)$ & NA \\
DAWN $^{\mathrm{e}}$ & $\mathrm{NA}$ & $1 / 107(0.93 \%)$ & NA \\
MR RESCUE $^{\mathrm{f}}$ & $\mathrm{NA}$ & $0 / 64(0 \%)$ & NA \\
THRACE $^{\mathrm{g}}$ & $\mathrm{NA}$ & $3 / 145(2.07 \%)$ & NA \\
\hline
\end{tabular}

Note:-NA indicates not applicable; AE, adverse event; TAE, total adverse event.

${ }^{a}$ No AE reported. Table 1 reports 4 groin complications; Table 5 reports 9 major adverse events at the access site.

${ }^{\mathrm{b}}$ Serious adverse events resulted in death, prolonged hospital stays, re-admission, or were severe or life-threatening. All minor events consisted of femoral hematomas.

'TAEs are not stratified on the basis of whether they were AEs or major adverse events.

${ }^{\mathrm{d}}$ No $\mathrm{AE}$ reported. A major adverse event was a groin hematoma requiring transfusion.

e No AE reported. A major adverse event was a vessel puncture-site hemorrhage requiring intervention.

${ }^{\mathrm{f}}$ No AE reported. A major adverse event consisted of 1 vessel dissection, though the vessel was not specified. There were no groin hematomas requiring intervention.

${ }^{g}$ No AE reported. Dissections and arterial perforations do not indicate a vessel.

obfuscated the relation of the complication to the procedural access site.

\section{CONCLUSIONS}

The rate of major access-site complications following a transfemoral approach has not been investigated in the context of neurointerventional procedures in prior studies. Our analysis demonstrates rates of major access-site complications from transfemoral access, similar to those reported in the cardiology literature and that may, in fact, be higher. However, transradial access is not without its limitations. The radial artery has a small diameter, which presents clear challenges when introducing the $8 \mathrm{~F}$ catheter required for cerebrovascular thrombectomies. We suggest further investigation into the feasibility and complication rates of alternative access sites for neurointerventional procedures. Furthermore, given the benefits of a transradial approach, there is a clear need for radial artery-specific cerebrovascular catheters, which are both compatible with radial access while also permitting successful cerebrovascular interventions.

\section{ACKNOWLEDGMENTS}

The authors acknowledge Vivian R. Hagerty and Hunter R. Carlock for their assistance in writing this article.

Disclosures: Brian M. Snelling-UNRELATED: Stock/Stock Options: RIST Neurovascular, Comments: preclinical neurovascular medical device company, no conflict related to submitted article.

\section{REFERENCES}

1. Windecker S, Kolh P, Alfonso F, et al; Authors/Task Force members. 2014 ESC/EACTS Guidelines on myocardial revascularization: the Task Force on Myocardial Revascularization of the European Society of Cardiology (ESC) and the European Association for Cardio-Thoracic Surgery (EACTS) developed with the special contribution of the European Association of Percutaneous Cardiovascular Interventions (EAPCI). Eur Heart J 2014;35:254149 CrossRef Medline

2. Roffi M, Patrono C, Collet JP, et al; ESC Scientific Document Group. 2015 ESC Guidelines for the management of acute coronary syndromes in patients presenting without persistent ST-segment elevation: Task Force for the Management of Acute Coronary Syndromes in Patients Presenting without Persistent ST-Segment Elevation of the European Society of Cardiology (ESC). Eur Heart J 2016;37:267-315 CrossRef Medline

3. Mehta SR, Jolly SS, Cairns J, et al; RIVAL Investigators. Effects of radial versus femoral artery access in patients with acute coronary syndromes with or without ST-segment elevation. J Am Coll Cardiol 2012;60:2490-99 CrossRef Medline

4. Valgimigli M, Gagnor A, Calabro P, et al; MATRIX Investigators. Radial versus femoral access in patients with acute coronary 
syndromes undergoing invasive management: a randomised multicentre trial. Lancet 2015;385:2465-76 CrossRef Medline

5. Snelling B, Sur S, Shah S, et al. Transradial cerebral angiography: techniques and outcomes. J Neurointerv Surg 2018;10:874-81 CrossRef Medline

6. Patel P, Haussen DC, Nogueira RG, et al. The neuro radialist. Interv Cardiol Clin 2020;9:75-86 CrossRef Medline

7. Jolly SS, Yusuf S, Cairns J, et al; RIVAL trial group. Radial versus femoral access for coronary angiography and intervention in patients with acute coronary syndromes (RIVAL): a randomised, parallel group, multicentre trial. Lancet 2011;377: 1409-20 CrossRef Medline

8. Lee DG, Lee DH, Shim JH, et. al. Feasibility of the transradial or the transbrachial approach in various neurointerventional procedures. Neurointervention 2015;10:74-81 CrossRef Medline

9. Haussen DC, Nogueira RG, DeSousa KG, et al. Transradial access in acute ischemic stroke intervention. J Neurointerv Surg 2016;8:24750 CrossRef Medline

10. Snelling BM, Sur S, Shah SS, et al. Transradial access: lessons learned from cardiology. J Neurointerv Surg 2018;10:487-92 CrossRef Medline

11. Snelling BM, Sur S, Shah SS, et al. Transradial approach for complex anterior and posterior circulation interventions: technical nuances and feasibility of using current devices. Oper Neurosurg (Hagerstown) 2019;17:293-302 CrossRef Medline

12. Dahm JB, Vogelgesang D, Hummel A, et al. A randomized trial of 5 vs. 6 French transradial percutaneous coronary interventions. Catheter Cardiovasc Interv 2002;57:172-76 CrossRef Medline

13. Nikoubashman O, Nikoubashman A, Büsen M, et al. Necessary catheter diameters for mechanical thrombectomy with ADAPT. AJNR Am J Neuroradiol 2017;38:2277-81 CrossRef Medline

14. Moher D, Liberati A, Tetzlaff J, et al; PRISMA Group. Preferred Reporting Items for Systematic Reviews and Meta-Analyses: the PRISMA Statement. Int J Surg 2010;8:336-41 CrossRef Medline

15. Liberati A, Altman DG, Tetzlaff J, et al. The PRISMA statement for reporting systematic reviews and meta-analyses of studies that evaluate health care interventions: explanation and elaboration. PLoS Med 2009;6:e1000100 CrossRef Medline

16. Pereira VM, Gralla J, Davalos A, et al. Prospective, multicenter, single-arm study of mechanical thrombectomy using Solitaire flow restoration in acute ischemic stroke. Stroke 2013;44:280207 CrossRef Medline

17. Smith WS, Sung G, Saver J, et al; Multi MERCI Investigators. Mechanical thrombectomy for acute ischemic stroke. Stroke 2008;39:1205-12 CrossRef Medline

18. Albers GW, Marks MP, Kemp S, et al; DEFUSE 3 Investigators. Thrombectomy for stroke at $\mathbf{6}$ to 16 hours with selection by perfusion imaging. N Engl J Med 2018;378:708-18 CrossRef Medline

19. Akins P, Amar A, Pakbaz R, et al; SWIFT Investigators. Complications of endovascular treatment for acute stroke in the SWIFT trial with Solitaire and Merci devices. AJNR Am J Neuroradiol 2014; 35:524-28 CrossRef Medline

20. Goyal M, Demchuk AM, Menon BK, et al; ESCAPE Trial Investigators. Randomized assessment of rapid endovascular treatment of ischemic stroke. N Engl J Med 2015;372:1019-30 CrossRef Medline

21. Jovin TG, Chamorro A, Cobo E, et al; REVASCAT Trial Investigators. Thrombectomy within $\mathbf{8}$ hours after symptom onset in ischemic stroke. N Engl J Med 2015;372:2296-2306 CrossRef Medline

22. Campbell BC, Mitchell PJ, Kleinig TJ, et al; EXTEND-IA Investigators. Endovascular therapy for ischemic stroke with perfusionimaging selection. N Engl J Med 2015;372:1009-18 CrossRef Medline

23. Nogueira RG, Jadhav AP, Haussen DC, et al; DAWN Trial Investigators. Thrombectomy $\mathbf{6}$ to $\mathbf{2 4}$ hours after stroke with a mismatch between deficit and infarct. $N$ Engl J Med 2018;378:11-21 CrossRef Medline

24. Kidwell CS, Jahan R, Gornbein J, et al; MR RESCUE Investigators. A trial of imaging selection and endovascular treatment for ischemic stroke. $N$ Engl J Med 2013;368:914-23 CrossRef Medline

25. Bracard S, Ducrocq X, Mas JL, et al; THRACE investigators. Mechanical thrombectomy after intravenous alteplase versus alteplase alone after stroke (THRACE): a randomised controlled trial. Lancet Neurol 2016;15:1138-47 CrossRef Medline

26. Mani R, Eisenberg RL, McDonald EJ Jr, et al. Complications of catheter cerebral arteriography: analysis of 5,000 procedures, I: criteria and incidence. AJR Am J Roentgenol 1978;131:861-65 CrossRef Medline

27. Sobolev M, Slovut DP, Lee Chang A, et al. Ultrasound-guided catheterization of the femoral artery: a systematic review and metaanalysis of randomized controlled trials. J Invasive Cardiol 2015;27: 318-23 Medline 